Dept. of Physiology, Biochemistry and Pharmacology,

College of Veterinary Medicine,

University of Mosul, Mosul, Iraq.

\title{
SERUM BIOCHEMICAL ALTRATIONS FOLLOWING ALLOXAN- INDUCED DIABETES MELLITUS IN THE LOCAL MALE DONKEY
}

(With 8 Tables and 2 Figures)

\author{
By \\ MAN S. KALO \\ (Received at 15/8/2011)
}

\section{التغيرات الكيميائية الحياتية الناتجة عن داء السكر المحدث بالألوكسان في

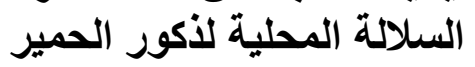

\section{معن سمير كلّو}

من المعروف أن حقن الألوكسان ينتج عنه إحداث داء السكر في النماذج الحيوية التجرييية.

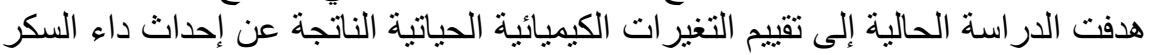

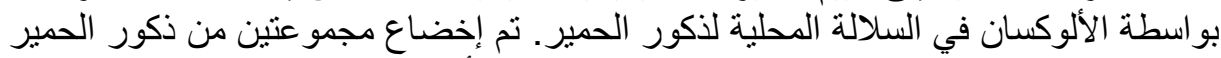

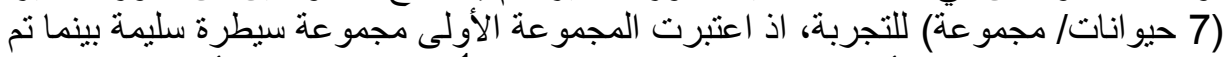

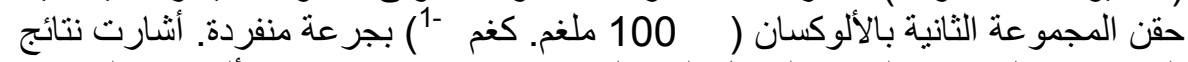

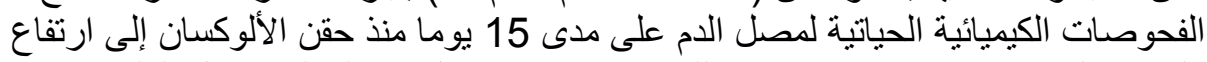

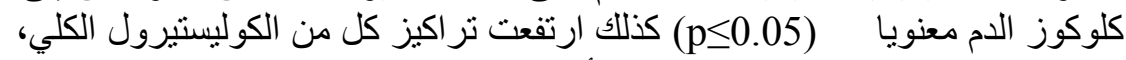

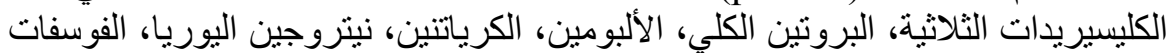

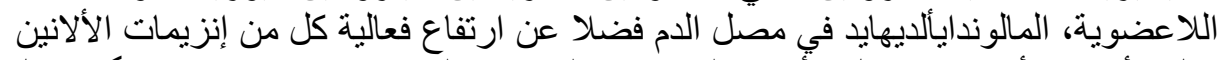

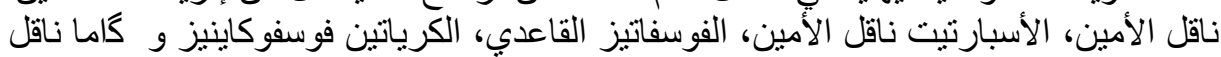

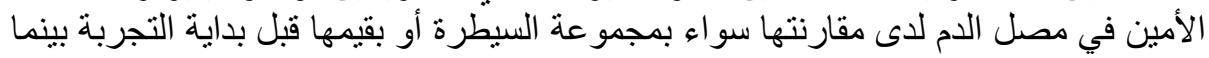

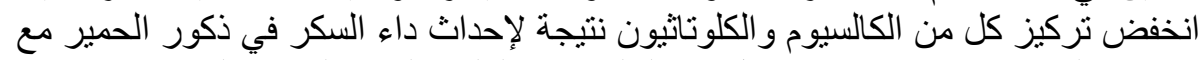

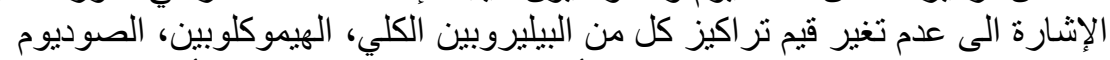

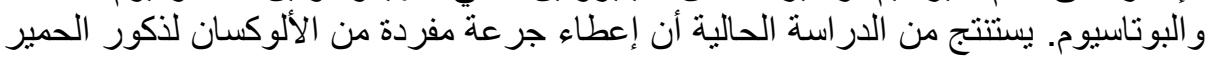

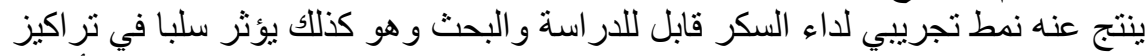

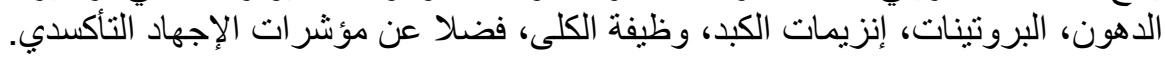

\section{SUMMARY}


Alloxan is known to induce diabetes mellitus in the experimental animals. The objective of this study is to evaluate the biochemical alterations resulted from alloxan- induced diabetes in the local breed of donkey males. Two groups of donkey males ( $\mathrm{n}=7$ each group) were subjected to the experiment, the $1^{\text {st }}$ one considered as a non diabetic control whereas the $2^{\text {nd }}$ injected with alloxan monohydrate $(100 \mathrm{mg}$. $\mathrm{kg}^{-1}$ ) with a single dose. Results of serum biochemical analysis along with 15 days from alloxan injection revealed in addition to the hyperglycemia, a significant $(\mathrm{p} \leq 0.05)$ elevation in total cholesterol, triglycerides, total protein, albumin, creatinine, blood urea nitrogen, inorganic phosphate, malondialdehyde serum concentration as well as increased activity of serum enzymes alanine aminotransferase, aspartate aminotransferase, alkaline phosphatase, creatine phosphokinase and $\gamma$ glutamyl transferase in respect to both control or baseline values. Serum calcium and glutathione concentration was declined as a result of experimental diabetes in male donkey with no significant changes in total bilirubin, hemoglobin, sodium and potassium concentrations. In conclusion, administration of a single dose of alloxan to the male donkey produced a reproducible model of diabetes mellitus which negatively affects the serum lipids, proteins, liver enzymes, kidney function and the markers of oxidative stress.

Key words: alloxan, diabetes, biochemical parameters, donkeys.

\section{INTRODUCTION}

Diabetes mellitus is a metabolic disease with a hallmark of tissue's inability to control the level of blood glucose resulted from a defect in insulin production (type 1), insulin response (type 2) or both with a probability to develop of some chronic complications related to the degree of glycemia (National diabetes fact sheet, 2007). These include nephropathy, retinopathy and neuropathy but arterial disease might be also developed in an unrelated manner to the degree of glycemia (Taylor and Agius, 1988). In addition to the hyperglycemia, diabetes patients show several metabolic disorders including hyperlipidemia and hypercholesterolemia (Taylor and Agius, 1988), as well as elevation of the activity of some enzymes including aminotransferases, alkaline phosphatase and gamma glutamyl transferase (McKenzie et al., 2006). The markers of oxidative stress like superoxide 
dismutase, catalase and total antioxidant capacity also might be elevated (Pacal et al., 2011; Wang et al., 2011).

Diabetes mellitus has been reported in laboratory and farm animals. Although there is a little informations about the role of genetic factors in the incidence of diabetes in animals (Kaneko et al., 1997), diabetes is well-defined in several species such as dogs (Alkharfy, 2009), sheep (Carver et al., 1995) and horses (Durham et al., 2009), also diabetes can be induced using a specific chemicals such as alloxan and streptozotocin, alloxan (2,4,5,6- tetraoxypyrimidin; 5,6 dioxyuracil) which is an oxidized product of uric acid can induce diabetes in animals through destroying the insulin secreting $\beta$ - cells in the pancreas (Medical dictionary). Alloxan exerts its diabetogenic activity when it is injected intravenously, intraperitoneally or subcutaneously in a dose dependent manner which is affected directly by animal species, route of administration, nutritional status and ambient temperature (Szkudelski, 2001).

The cytotoxic action of alloxan and it's product (dialuric acid) is mediated by enhancing of the level of reactive oxygen species causing rapid damage to the target cells (Szkudelski, 2001). Nowadays alloxan is widely used for creation of experimental diabetic status in various biological models which includes, rabbits (Okamoto et al., 1990; Gupta et al., 2010), cats (Reiser et al., 1987; Ladosky and Fonteles, 1988), sheep (Smith and Prior, 1984), dogs (Jelodar et al., 2007; Sboui et al., 2010), rats (Ghosh et al., 2010) and mice (Paul et al., 2011).

To our knowledge, a finite number of studies focused on deleterious effects of diabetes mellitus induction in the equine especially the local breed of donkeys in Iraq. So the aim of this study was oriented toward the induction of experimental diabetes in donkeys and the investigation about the serum biochemical consequence during a limited period.

\section{MATERIALS and METHODS}

Animals: Fourteen local breed donkey males with weight range 155$180 \mathrm{~kg}$ and age 2- 3.5 years were used as a biological model for the major study while another group of six donkeys were subjected to preliminary study for determining the effective dose of alloxan, donkeys emplaced in an ideal byre for large animals in the farm of the College of Veterinary Medicine, University of Mosul. Animals fed daily with a 
mixture of barley and hay 3:1 with continuous providing of drinking water, All animals underwent a 32 hour of fasting period.

\section{Induction of diabetes}

Preparation and injection of alloxan: The dose of alloxan monohydrate (Molekula Ltd., UK) for each animal was weighted away from direct light as possible just before injection according to the animal's body weight, immediately dissolved in physiological saline $(0.9 \% \mathrm{NaCl})$ in a manner to meet a final volume of injection equal to 20 $\mathrm{ml}$ per each animal. Alloxan injected as soon as it prepared intravenously within three minutes. Experimental design

Preliminary study: a series of alloxan doses; 75, 100 and $125 \mathrm{mg} . \mathrm{kg}^{-1}$ body weight used to fix the effective dose in local breed of donkeys. Each level of dose injected to two donkeys in a single injection. The ideal diabetogenic dose was established using serum glucose level after forty- eight hours as an indicator.

Major study: Basing on the foundations of the preliminary study, the dose of $100 \mathrm{mg} . \mathrm{kg}^{-1}$ was the ideal for the induction of diabetes in donkeys.

Two groups of donkey males was subjected to the experimental induction of diabetes as follow:

- Control: Injected with $20 \mathrm{ml}$ of physiological saline intravenously.

- Diabetic: Injected with alloxan in a single dose of $100 \mathrm{mg}$. $\mathrm{kg}^{-1}$ body weight intravenously.

\section{Blood specimens:}

Collection of blood: Five $\mathrm{ml}$ of venous blood of the fasted donkeys was obtained from jugular vein in a glass centrifuge tubes at each time, an additional one $\mathrm{ml}$ of blood was obtained in EDTA tubes for estimation of hemoglobin concentration. Specimens collected during the major study at the times, zero, 24 hours, 48 hours, 72 hours, 7 days and 15 days respectively after alloxan injection.

Separation of serum: Blood in the centrifuge tubes allowed for coagulation then centrifuged at $1500 \mathrm{rpm}$ for twenty minutes (Fox et al., 1997) using bench top centrifuge (Wagtech, UK). Supernatant serum aspirated using disposable Pasteur pipettes and kept in polyethylene containers at $-20{ }^{\circ} \mathrm{C}$.

Biochemical tests: All biochemical tests were performed in the Central Lab. of Researches, College of Veterinary Medicine, University of Mosul. Parameters including glucose, total cholesterol, triglycerides, albumin, total bilirubin, creatinine, blood urea nitrogen and inorganic 
phosphate were assayed using photometric kits manufactured by Fabricant BioLabo SA. France. Activity of serum enzymes including alanine aminotransferase (ALT), aspartate aminotransferase (AST), alkaline phosphatase (ALP) and creatine phosphokinase (CPK) was estimated using photometric kits manufactured by BioMerieux SA. France while gamma glutamyl transferase GGT and amylase activity was determined using specific kits of Reflotron ${ }^{\circledR}$ Plus chemistry analyzer, Roche. USA. The absorbance of samples was observed using UV/ Visible spectrophotometer Biotech 2601. UK. Concentrations of serum electrolytes including sodium $\left(\mathrm{Na}^{+}\right)$, potassium $\left(\mathrm{K}^{+}\right)$and calcium $\left(\mathrm{Ca}^{+2}\right)$ were detected using automated electrolyte analyzer SmartLyte. Diamond. USA.

Serum total protein estimated photometrically using Biuret reagent (Burtis and Ashwood 1999) concentration of unknown serum samples assessed by application of calibration curve whereas hemoglobin $(\mathrm{Hb})$ concentration was determined in the EDTA- whole blood samples using fully automated veterinary hematology coulter Abacus Junior. Diatron. Italy. Photometric analytical methods were used to determine the concentration of both serum glutathione (GSH) (Burtis and Ashwood 1999) and malondialdehyde (MDA) (Beuge and Aust, 1978). The concentration of both was calculated using extinction coefficient.

Data analysis: The quantitative data were subjected to two- way analysis of variance according to Steel and Torrie, (1980). Mean differences were statistically compared using $\mathrm{p} \leq 0.05$ as a level of significance by Duncan multiple test (Duncan, 1955). Analysis was achieved by means of computer software, statistical package for social sciences SPSS.

\section{RESULTS}

Preliminary study: As shown in figure 1, the ideal diabetogenic dose of alloxan in the local breed of donkey males might be $100 \mathrm{mg} \cdot \mathrm{kg}^{-1}$ which resulted in an elevation in serum glucose whereas the single dose of $75 \mathrm{mg} \cdot \mathrm{kg}^{-1}$ was insufficient to induce a satisfactory diabetic hyperglycemia after 48 hours. The administration of dose $125 \mathrm{mg} \cdot \mathrm{kg}^{-1}$ resulted in a high toxicity just after several hours of injection where worthy mentionable that one of the animals received alloxan dose 125 mg. $\mathrm{kg}^{-1}$ perished after about 17 hours and the remainder one perished after 28 hours since injection time. 


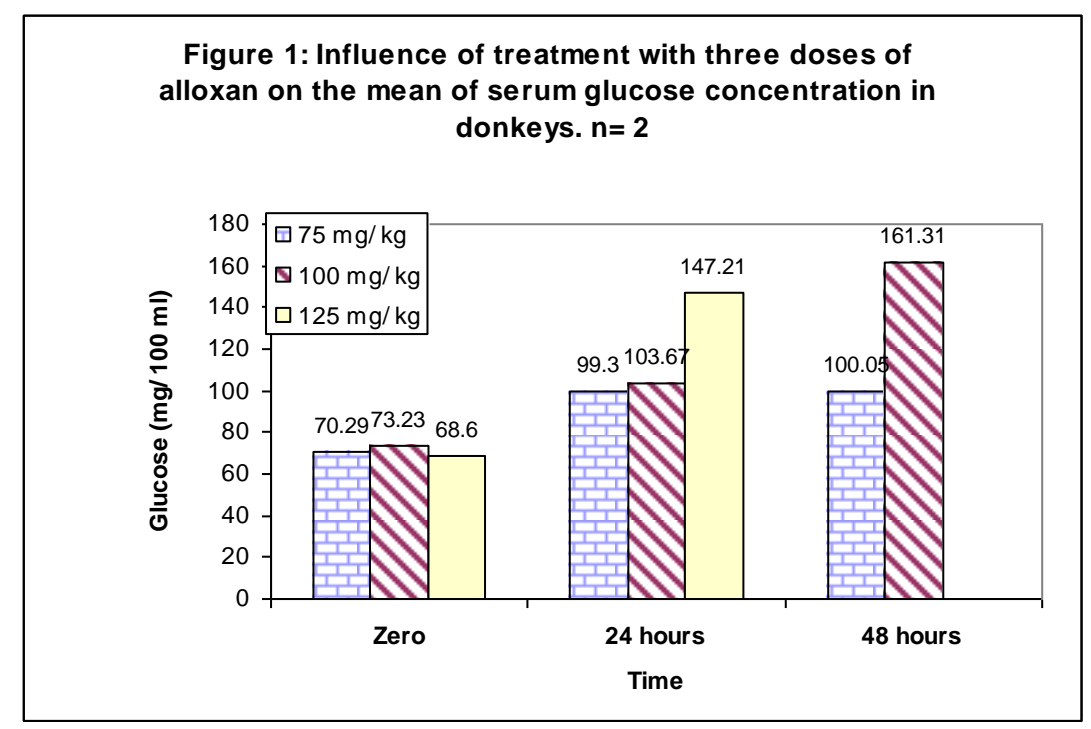

Major study: a significant gradual elevation $(\mathrm{p} \leq 0.05)$ in serum glucose was observed in the alloxan- treated group compared with normal control since 24 hours after alloxan injection reaching the more significance in the days 7 and 15 where there is a statistical difference of there values in comparison with control (figure 2).

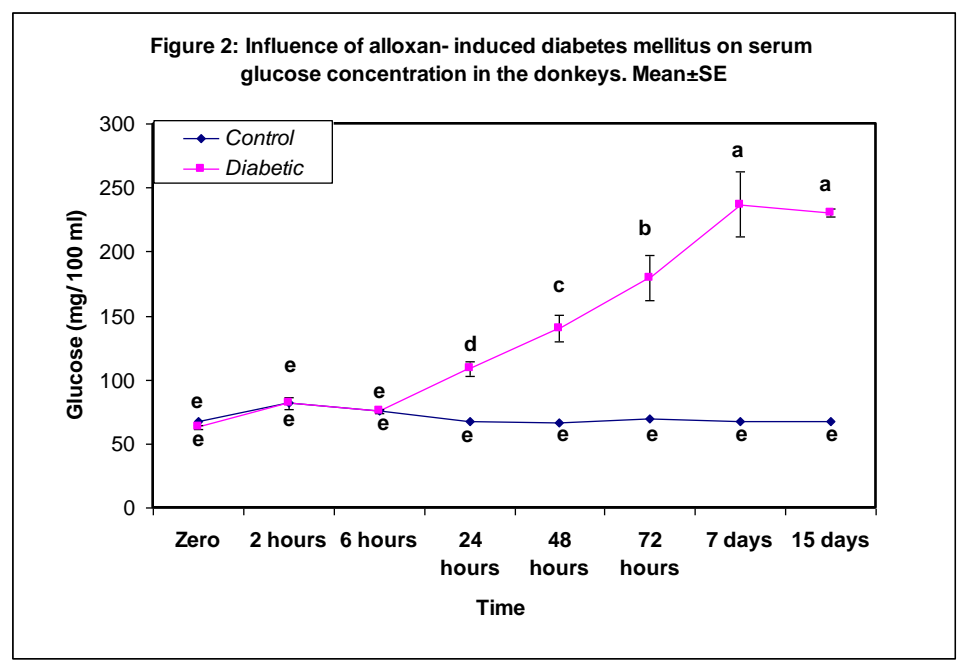

Serum total cholesterol (TC) level start to elevate after 24 hours of treatment as a result of induced diabetes relative to both zero time or control group, total cholesterol continued to elevate keeping on the same 
levels throughout 48, 72 hours and 7 days. The observed value in the $15^{\text {th }}$ day was slightly decreased however it stilled statistically parallel to the value of $7^{\text {th }}$ day (Table 1).

Table 1: Influence of alloxan- induced diabetes mellitus on serum total cholesterol and triglycerides concentrations in donkeys.

\begin{tabular}{|c|c|c|c|c|c|c|}
\hline \multicolumn{7}{|c|}{$\mathrm{TC}\left(\mathrm{mg} .100 \mathrm{ml}^{-1}\right)$} \\
\hline $\begin{array}{l}\text { Time } \\
\text { Groups }\end{array}$ & Zero & 24 hours & 48 hours & 72 hours & 7 days & 15 days \\
\hline Control & $\begin{array}{c}79.95 \\
\pm 0.71^{\mathrm{d}}\end{array}$ & $\begin{array}{c}81.70 \\
\pm 0.62^{d}\end{array}$ & $\begin{array}{c}80.39 \\
\pm 1.43^{\mathrm{d}}\end{array}$ & $\begin{array}{c}79.82 \\
\pm 1.84^{\mathrm{d}}\end{array}$ & $\begin{array}{l}80.45 \\
\pm 1.93^{\mathrm{d}}\end{array}$ & $\begin{array}{c}69.25 \\
\pm 11.49^{\mathrm{d}}\end{array}$ \\
\hline Diabetic & $\begin{array}{c}78.50 \\
\pm 1.10^{\mathrm{d}}\end{array}$ & $\begin{array}{l}122.56 \\
\pm 4.39^{\circ}\end{array}$ & $\begin{array}{c}143.87 \\
\pm 4.55^{\mathrm{ab}}\end{array}$ & $\begin{array}{l}155.05 \\
\pm 6.84^{\mathrm{a}}\end{array}$ & $\begin{array}{c}147.47 \\
\pm 7.77^{\text {ab }}\end{array}$ & $\begin{array}{c}133.25 \\
\pm 4.91 \mathrm{bc}\end{array}$ \\
\hline \multicolumn{7}{|c|}{ TG $\left(\mathrm{mg} .100 \mathrm{ml}^{-1}\right)$} \\
\hline Control & $\begin{array}{l}49.15 \pm \\
6.67 \mathrm{de}\end{array}$ & $\begin{array}{c}54.54 \\
\pm 6.56 \mathrm{de}\end{array}$ & $\begin{array}{c}44.14 \\
\pm 5.29^{\mathrm{e}}\end{array}$ & $\begin{array}{c}57.90 \\
\pm 3.19^{\mathrm{c}-\mathrm{e}}\end{array}$ & $\begin{array}{c}56.67 \\
\pm 3.75^{\text {c-e }}\end{array}$ & $\begin{array}{c}56.65 \\
\pm 2.44^{\text {c-e }}\end{array}$ \\
\hline Diabetic & $\begin{array}{r}61.56 \\
\pm 1.07^{\mathrm{cd}}\end{array}$ & $\begin{array}{r}69.01 \\
\pm .67^{\mathrm{c}}\end{array}$ & $\begin{array}{c}89.7 \\
\pm 3.70^{\mathrm{b}}\end{array}$ & $\begin{array}{l}115.43 \\
\pm 5.75^{\mathrm{a}}\end{array}$ & $\begin{array}{c}97.62 \\
\pm 4.37^{\mathrm{b}}\end{array}$ & $\begin{array}{c}93.42 \\
\pm 4.04^{\mathrm{b}}\end{array}$ \\
\hline
\end{tabular}

- Values are expressed as mean \pm SE

- Different letters in the columns or rows refers to a significant difference $\mathrm{p} \leq 0.05$

- $\mathrm{n}=7$

The level of serum total triglycerides (TG) also elevated after 24 hours from alloxan injection and so on reaching the peak level at 72 hours which statistically considered the highest value $(\mathrm{p} \leq 0.05)$ compared with either control group or zero hour. Triglycerides level of the diabetic animals showed significant decline outset from the $7^{\text {th }}$ day to the $15^{\text {th }}$ day in comparison with the value observed after 72 hours of diabetes induction (Table 1).

There was an elevation in the serum total protein (TP) in the diabetic donkeys after 72 hours of alloxan injection till the end of $15^{\text {th }}$ day, the elevation was significant $(\mathrm{p} \leq 0.05)$ when compared with either control or with the baseline level. Serum albumin concentration also elevated in the same manner of that related to total protein with a notification that the value of $15^{\text {th }}$ day was statistically considered the highest (Table 2). 
Table 2: Influence of alloxan- induced diabetes mellitus on serum proteins concentrations in donkeys.

\begin{tabular}{|c|c|c|c|c|c|c|}
\hline \multicolumn{7}{|c|}{$\mathrm{TP}\left(\mathrm{g} .100 \mathrm{ml}^{-1}\right)$} \\
\hline $\begin{array}{l}\text { Time } \\
\text { Groups }\end{array}$ & Zero & 24 hours & 48 hours & 72 hours & 7 days & 15 days \\
\hline Control & $\begin{array}{c}6.73 \\
\pm 0.06^{\mathrm{b}} \\
\end{array}$ & $\begin{array}{c}6.30 \\
\pm 0.27^{\mathrm{b}} \\
\end{array}$ & $\begin{array}{r}6.60 \\
\pm 0.24^{\mathrm{b}} \\
\end{array}$ & $\begin{array}{c}6.68 \\
\pm 0.09^{\mathrm{b}} \\
\end{array}$ & $\begin{array}{c}6.68 \\
\pm 0.08^{\mathrm{b}} \\
\end{array}$ & $\begin{array}{c}6.60 \\
\pm 0.06^{\mathrm{b}} \\
\end{array}$ \\
\hline Diabetic & $\begin{array}{c}6.76 \\
\pm 0.06^{\mathrm{b}} \\
\end{array}$ & $\begin{array}{c}6.59 \\
\pm 0.05^{\mathrm{b}} \\
\end{array}$ & $\begin{array}{c}6.71 \\
\pm 0.24^{\mathrm{b}} \\
\end{array}$ & $\begin{array}{c}7.24 \\
\pm 0.10^{\text {a }} \\
\end{array}$ & $\begin{array}{r}7.59 \\
\pm 0.05^{\text {a }} \\
\end{array}$ & $\begin{array}{c}7.64 \\
\pm 0.05^{\text {a }} \\
\end{array}$ \\
\hline \multicolumn{7}{|c|}{ Albumin (g.100 ml $\left.{ }^{-1}\right)$} \\
\hline Control & $\begin{array}{c}3.08 \\
\pm 0.04^{c}\end{array}$ & $\begin{array}{c}3.03 \\
\pm 0.04^{\mathrm{c}}\end{array}$ & $\begin{array}{c}3.13 \\
\pm 0.03^{\mathrm{c}}\end{array}$ & $\begin{array}{c}3.10 \\
\pm 0.02^{\mathrm{c}}\end{array}$ & $\begin{array}{c}3.07 \\
\pm 0.05^{\mathrm{c}}\end{array}$ & $\begin{array}{r}3.15 \\
\pm 0.03^{c}\end{array}$ \\
\hline Diabetic & $\begin{array}{r}3.12 \\
\pm 0.03^{c}\end{array}$ & $\begin{array}{c}3.16 \\
\pm 0.03^{c}\end{array}$ & $\begin{array}{c}3.24 \\
\pm 0.02^{\mathrm{c}}\end{array}$ & $\begin{array}{c}3.79 \\
\pm 0.08^{\mathrm{b}}\end{array}$ & $\begin{array}{c}3.90 \\
\pm 0.19^{\mathrm{b}}\end{array}$ & $\begin{array}{c}4.21 \\
\pm 0.10^{\text {a }}\end{array}$ \\
\hline
\end{tabular}

- Values are expressed as mean $\pm \mathrm{SE}$

- Different letters in the columns or rows refers to a significant difference $\mathrm{p} \leq 0.05$

- $\mathrm{n}=7$

The activity of serum alanine aminotransferase (ALT) start to increase significantly $(\mathrm{p} \leq 0.05)$ after 24 hours of the alloxan injection. The peak activity was shown at 48 and 72 hours then it revealed a significant drop $(\mathrm{p} \leq 0.05)$ in both $7^{\text {th }}$ and $15^{\text {th }}$ days but it maintained more significant $(p \leq 0.05)$ than those of control or baseline activity levels (Table 3).

Aspartate aminotransferase (AST) activity showed a significant $(\mathrm{p} \leq 0.05)$ elevation at 48 hours compared with control and zero hour (Table 3). The value raised significantly at 72 hours and 7 days respectively while it returns to drop $(\mathrm{p} \leq 0.05)$ in the $15^{\text {th }}$ day to be around the value of 72 hours.

Table 3 also show an increase in the activity of alkaline phosphatase (ALP) at 24 hours in the alloxan- treated group relative to control and zero hour, the increase in turns to be distinct at 48 hours reaching the peak level at 72 hours then ALP activity commenced to reduce in $7^{\text {th }}$ and $15^{\text {th }}$ days to stable around the value of 24 hours.

Creatine phosphokinase (CPK) activity increased significantly $(\mathrm{p} \leq 0.05)$ at 24 hours of the diabetic donkeys compared to control and zero time The significance increased at 48 hours then declined to approach the level of that shown at 24 hours while the end value observed after 15 days of treatment was significantly $(\mathrm{p} \leq 0.05)$ less than those of 72 hours and 7 days but still significant relative to control (Table 3). 
Gamma glutamyl transferase (GGT) activity elevated significantly at 24 hours compared to control and zero time. At 48 hours, the value was statistically higher than that of 24 hours while the more significant $(\mathrm{p} \leq 0.05)$ elevation was recognized at 72 hours, 7 and 15 days (Table 3). Amylase activity fluctuates during the period of experiment however no distinct significance observed (Table 3).

Table 3: Influence of alloxan- induced diabetes mellitus on serum enzymes activity in donkeys.

\begin{tabular}{|c|c|c|c|c|c|c|}
\hline \multicolumn{7}{|c|}{$\operatorname{ALT}\left(\mathrm{U} . L^{-1}\right)$} \\
\hline $\begin{array}{c}\text { Time } \\
\text { Groups }\end{array}$ & Zero & 24 hours & 48 hours & 72 hours & 7 days & 15 days \\
\hline Control & $\begin{array}{c}63.83 \\
\pm 0.07^{\mathrm{d}}\end{array}$ & $\begin{array}{c}61.0 \\
\pm 1.15^{\mathrm{d}}\end{array}$ & $\begin{array}{c}61.83 \\
\pm 0.94^{\mathrm{d}}\end{array}$ & $\begin{array}{c}60.0 \\
\pm 2.16^{\mathrm{d}}\end{array}$ & $\begin{array}{c}63.83 \\
\pm 0.87^{\mathrm{d}}\end{array}$ & $\begin{array}{l}63.66 \\
\pm 1.0^{\mathrm{d}}\end{array}$ \\
\hline Diabetic & $\begin{array}{c}63.33 \\
\pm 0.98^{\mathrm{d}}\end{array}$ & $\begin{array}{c}68.33 \\
\pm 1.05^{c}\end{array}$ & $\begin{array}{c}81.0 \\
\pm 1.15^{\text {a }}\end{array}$ & $\begin{array}{c}80.16 \\
\pm 1.40^{\mathrm{a}}\end{array}$ & $\begin{array}{c}74.33 \\
\pm 1.81^{\mathrm{b}}\end{array}$ & $\begin{array}{c}71.33 \\
\pm 1.566^{\mathrm{bc}}\end{array}$ \\
\hline \multicolumn{7}{|c|}{$\operatorname{AST}\left(\mathrm{U}^{\mathrm{L}} \mathrm{L}^{-1}\right)$} \\
\hline Control & $\begin{array}{r}36.0 \\
\pm 1.21^{\mathrm{d}}\end{array}$ & $\begin{array}{c}35.83 \\
\pm 0.74^{d}\end{array}$ & $\begin{array}{c}35.83 \\
\pm 0.65^{\mathrm{d}}\end{array}$ & $\begin{array}{c}36.33 \\
\pm 1.08^{\mathrm{d}}\end{array}$ & $\begin{array}{c}36.66 \\
\pm 0.95^{\mathrm{d}}\end{array}$ & $\begin{array}{c}36.50 \\
\pm 1.64^{\mathrm{d}}\end{array}$ \\
\hline Diabetic & $\begin{array}{c}36.33 \\
\pm 0.76^{\mathrm{d}}\end{array}$ & $\begin{array}{c}36.83 \\
\pm 0.98^{\mathrm{d}}\end{array}$ & $\begin{array}{c}44.33 \\
\pm 0.98^{c}\end{array}$ & $\begin{array}{c}60.66 \\
\pm 2.36^{\mathrm{b}}\end{array}$ & $\begin{array}{r}66.50 \\
\pm 1.60^{\mathrm{a}}\end{array}$ & $\begin{array}{c}59.33 \\
\pm 1.45^{\mathrm{b}}\end{array}$ \\
\hline \multicolumn{7}{|c|}{ ALP $\left(U^{\prime} \cdot L^{-1}\right)$} \\
\hline Control & $\begin{array}{l}156.83 \\
\pm 6.03^{d}\end{array}$ & $\begin{array}{l}154.16 \\
\pm 5.26^{d}\end{array}$ & $\begin{array}{l}161.33 \\
\pm 4.03^{\mathrm{d}}\end{array}$ & $\begin{array}{l}167.16 \\
\pm 3.87^{\mathrm{d}}\end{array}$ & $\begin{array}{r}157.50 \\
\pm 4.01^{d}\end{array}$ & $\begin{array}{c}163.0 \\
\pm 4.57^{\mathrm{d}}\end{array}$ \\
\hline Diabetic & $\begin{array}{l}163.83 \\
\pm 5.73^{\mathrm{d}}\end{array}$ & $\begin{array}{l}210.66 \\
\pm 7.32^{c}\end{array}$ & $\begin{array}{r}262.50 \\
\pm 11.96^{\mathrm{b}}\end{array}$ & $\begin{array}{l}310.83 \\
\pm 9.76^{\mathrm{a}}\end{array}$ & $\begin{array}{l}213.50 \\
\pm 5.53^{c}\end{array}$ & $\begin{array}{l}203.50 \\
\pm 8.60^{c}\end{array}$ \\
\hline \multicolumn{7}{|c|}{ CPK $\left(\mathrm{U}^{\mathrm{L}} \mathrm{L}^{-1}\right)$} \\
\hline Control & $\begin{array}{r}126.50 \\
\pm 3.07^{\mathrm{d}}\end{array}$ & $\begin{array}{l}124.50 \\
\pm 2.83^{\mathrm{d}}\end{array}$ & $\begin{array}{l}131.66 \\
\pm 1.74^{\mathrm{d}}\end{array}$ & $\begin{array}{l}130.16 \\
\pm 2.15^{\mathrm{d}}\end{array}$ & $\begin{array}{r}126.50 \\
\pm 1.83^{d}\end{array}$ & $\begin{array}{l}129.16 \\
\pm 2.08^{\mathrm{d}}\end{array}$ \\
\hline Diabetic & $\begin{array}{r}129.83 \\
\pm 0.89^{d}\end{array}$ & $\begin{array}{r}199.66 \\
\pm 7.92^{\mathrm{b}}\end{array}$ & $\begin{array}{c}222.0 \\
\pm 5.70^{\mathrm{a}}\end{array}$ & $\begin{array}{r}192.83 \\
\pm 6.11^{\mathrm{b}}\end{array}$ & $\begin{array}{r}196.0 \\
\pm 4.93^{\mathrm{b}}\end{array}$ & $\begin{array}{r}162.83 \\
\pm 10.34^{\mathrm{c}}\end{array}$ \\
\hline \multicolumn{7}{|c|}{ GGT (U.L $\left.{ }^{-1}\right)$} \\
\hline Control & $\begin{array}{r}37.0 \\
\pm 0.85^{\mathrm{d}}\end{array}$ & $\begin{array}{c}41.33 \\
\pm 0.88^{\mathrm{d}}\end{array}$ & $\begin{array}{c}39.0 \\
\pm 1.09^{\mathrm{d}}\end{array}$ & $\begin{array}{c}39.50 \\
\pm 1.23^{\mathrm{d}}\end{array}$ & $\begin{array}{r}39.50 \\
\pm 0.84^{d}\end{array}$ & $\begin{array}{c}37.50 \\
\pm 1.66^{\mathrm{d}}\end{array}$ \\
\hline Diabetic & $\begin{array}{c}37.66 \\
\pm 0.84^{d}\end{array}$ & $\begin{array}{c}67.33 \\
\pm 2.09^{\mathrm{c}}\end{array}$ & $\begin{array}{c}75.66 \\
\pm 2.65^{\mathrm{b}}\end{array}$ & $\begin{array}{c}81.83 \\
\pm 1.24^{\mathrm{a}}\end{array}$ & $\begin{array}{c}80.33 \\
\pm 2.13^{\mathrm{a}}\end{array}$ & $\begin{array}{c}82.0 \\
\pm 1.03^{\mathrm{a}}\end{array}$ \\
\hline \multicolumn{7}{|c|}{ Amylase (U.L $\left.{ }^{-1}\right)$} \\
\hline Control & $\begin{array}{c}59.833 \\
\pm 1.74^{\text {ab }}\end{array}$ & $\begin{array}{l}62.833 \\
\pm 0.79^{\mathrm{a}}\end{array}$ & $\begin{array}{l}62.333 \\
\pm 1.11^{\mathrm{a}}\end{array}$ & $\begin{array}{c}61.833 \\
\pm 1.53 \text { ab }\end{array}$ & $\begin{array}{l}63.333 \\
\pm 0.71^{\text {a }}\end{array}$ & $\begin{array}{c}62.0 \\
\pm 0.85^{\mathrm{ab}}\end{array}$ \\
\hline Diabetic & $\begin{array}{l}57.666 \\
\pm 1.30^{\mathrm{b}}\end{array}$ & $\begin{array}{l}62.666 \\
\pm 1.56^{\mathrm{a}}\end{array}$ & $\begin{array}{c}60.833 \\
\pm 2.60 \text { ab }\end{array}$ & $\begin{array}{c}59.333 \\
\pm 1.85 \text { ab }\end{array}$ & $\begin{array}{l}62.166 \\
\pm 0.79^{a}\end{array}$ & $\begin{array}{c}61.166 \\
\pm 1.40^{\text {ab }}\end{array}$ \\
\hline
\end{tabular}

- Values are expressed as mean $\pm \mathrm{SE}$

- Different letters in the columns or rows refers to a significant difference $\mathrm{p} \leq 0.05$

- $\mathrm{n}=7$ 
Neither serum total bilirubin nor blood hemoglobin $(\mathrm{Hb})$ concentrations were altered as a result of experimental diabetes in male donkey (Table 4). Sodium $\left(\mathrm{Na}^{+}\right)$in serum concentration did not affected by the process of diabetes induction (Table 5) likewise the concentration of serum potassium $\left(\mathrm{K}^{+}\right)$yet $\mathrm{K}^{+}$manifests a mildly fluctuation in comparison with control however there is no distinct significance $(\mathrm{p} \leq 0.05)$.

Table 4: Influence of alloxan- induced diabetes mellitus on serum total bilirubin and hemoglobin concentrations in donkeys.

\begin{tabular}{|l|c|c|c|c|c|c|}
\hline \multicolumn{7}{|c|}{ Total bilirubin $\left(\mathrm{mg} .100 \mathrm{ml}^{-1}\right)$} \\
\hline $\begin{array}{c}\text { Time } \\
\text { Groups }\end{array}$ & Zero & 24 hours & 48 hours & 72 hours & 7 days & 15 days \\
\hline Control & $\begin{array}{c}0.27 \\
\pm 0.01^{\mathrm{a}-\mathrm{c}}\end{array}$ & $\begin{array}{c}0.28 \\
\pm 0.01^{\mathrm{a}-\mathrm{c}}\end{array}$ & $\begin{array}{c}0.27 \\
\pm 0.01^{\mathrm{a}-\mathrm{c}}\end{array}$ & $\begin{array}{c}0.29 \\
\pm 0.00^{\mathrm{ab}}\end{array}$ & $\begin{array}{c}0.30 \\
\pm 0.00^{\mathrm{a}}\end{array}$ & $\begin{array}{c}0.30 \\
\pm 0.00^{\mathrm{a}}\end{array}$ \\
\hline Diabetic & 0.26 & 0.25 & 0.25 & 0.025 & 0.27 & 0.27 \\
& $\pm 0.01^{\mathrm{bc}}$ & $\pm 0.01^{\mathrm{bc}}$ & $\pm 0.01^{\mathrm{bc}}$ & $\pm 0.01^{\mathrm{bc}}$ & $\pm 0.01^{\mathrm{a}-\mathrm{c}}$ & $\pm 0.01^{\mathrm{a}-\mathrm{c}}$ \\
\hline \multicolumn{7}{|c|}{$\left.\mathrm{Hb}^{\mathrm{g} .100 \mathrm{ml}^{-1}}\right)$} \\
\hline Control & 8.56 & 8.04 & 8.39 & 8.29 & 8.07 & 8.35 \\
& $\pm 0.25^{\mathrm{a}}$ & $\pm 0.39^{\mathrm{a}}$ & $\pm 0.25^{\mathrm{a}}$ & $\pm 0.31^{\mathrm{a}}$ & $\pm 0.21^{\mathrm{a}}$ & $\pm 0.28^{\mathrm{a}}$ \\
\hline Diabetic & 8.36 & 8.14 & 8.52 & 8.24 & 8.32 & 7.95 \\
& $\pm 0.22^{\mathrm{a}}$ & $\pm 0.57^{\mathrm{a}}$ & $\pm 0.30^{\mathrm{a}}$ & $\pm 0.29^{\mathrm{a}}$ & $\pm 0.30^{\mathrm{a}}$ & $\pm 0.27^{\mathrm{a}}$ \\
\hline
\end{tabular}

- Values are expressed as mean $\pm \mathrm{SE}$

- Different letters in the columns or rows refers to a significant difference $\mathrm{p} \leq 0.05$

- $\mathrm{n}=7$

Table 5: Influence of alloxan- induced diabetes mellitus on serum electrolytes concentration in donkeys.

\begin{tabular}{|c|c|c|c|c|c|c|}
\hline \multicolumn{7}{|c|}{$\mathrm{Na}^{+}\left(\mathrm{mmol} . \mathrm{L}^{-1}\right)$} \\
\hline $\begin{array}{l}\text { Time } \\
\text { Groups }\end{array}$ & Zero & 24 hours & 48 hours & 72 hours & 7 days & 15 days \\
\hline Control & $\begin{array}{r}103.0 \\
\pm 2.69^{\mathrm{a}}\end{array}$ & $\begin{array}{c}101.0 \\
\pm 1.96^{\mathrm{a}}\end{array}$ & $\begin{array}{l}102.16 \\
\pm 2.25^{\text {a }}\end{array}$ & $\begin{array}{l}101.16 \\
\pm 4.10^{\text {a }}\end{array}$ & $\begin{array}{c}98.16 \\
\pm 2.62^{a}\end{array}$ & $\begin{array}{c}97.33 \\
\pm 1.56^{\mathrm{a}}\end{array}$ \\
\hline Diabetic & $\begin{array}{r}97.50 \\
\pm 3.08^{\text {a }} \\
\end{array}$ & $\begin{array}{l}102.50 \\
\pm 2.81^{\text {a }} \\
\end{array}$ & $\begin{array}{r}104.66 \\
\pm 3.91^{\text {a }} \\
\end{array}$ & $\begin{array}{r}96.50 \\
\pm 3.87^{\text {a }} \\
\end{array}$ & $\begin{array}{c}98.83 \\
\pm 1.62^{\text {a }} \\
\end{array}$ & $\begin{array}{c}98.83 \\
\pm 1.49^{\mathrm{a}} \\
\end{array}$ \\
\hline \multicolumn{7}{|c|}{$\mathrm{K}^{+}\left(\mathrm{mmol}^{\left.-\mathrm{L}^{-1}\right)}\right.$} \\
\hline Control & $\begin{array}{r}5.42 \\
\pm 0.16^{\text {ab }}\end{array}$ & $\begin{array}{c}5.22 \\
\pm 0.05^{\text {a-c }}\end{array}$ & $\begin{array}{c}5.41 \\
\pm 0.10^{a b}\end{array}$ & $\begin{array}{c}5.35 \\
\pm 0.10^{\mathrm{a}-\mathrm{c}}\end{array}$ & $\begin{array}{c}5.45 \\
\pm 0.12^{\text {a }}\end{array}$ & $\begin{array}{c}5.18 \\
\pm 0.04^{\text {bc }}\end{array}$ \\
\hline Diabetic & $\begin{array}{c}5.08 \\
\pm 0.04^{\mathrm{c}}\end{array}$ & $\begin{array}{r}5.11 \\
\pm 0.03^{\mathrm{c}}\end{array}$ & $\begin{array}{c}5.09 \\
\pm 0.05^{\mathrm{c}}\end{array}$ & $\begin{array}{c}5.12 \\
\pm 0.03^{\mathrm{c}}\end{array}$ & $\begin{array}{c}5.16 \\
\pm 0.02^{\mathrm{bc}}\end{array}$ & $\begin{array}{c}5.11 \\
\pm 0.08^{\mathrm{c}}\end{array}$ \\
\hline
\end{tabular}

- Values are expressed as mean $\pm \mathrm{SE}$

- Different letters in the columns or rows refers to a significant difference $\mathrm{p} \leq 0.05$

- $\mathrm{n}=7$ 
Calcium concentration decreased significantly $(p \leq 0.05)$ after 24 hours compared to control and baseline value (Table 6). Inorganic phosphate concentration exhibited an obvious increase since 24 hours of treatment and so all over the period of experiment (Table 6).

Table 6: Influence of alloxan- induced diabetes mellitus on serum calcium and inorganic phosphate concentrations in donkeys.

\begin{tabular}{|c|c|c|c|c|c|c|}
\hline $\begin{array}{c}\text { Time } \\
\text { Groups }\end{array}$ & Zero & 24 hours & 48 hours & 72 hours & 7 days & 15 days \\
\hline Control & $\begin{array}{c}1.520 \\
\pm 0.03^{\mathrm{a}}\end{array}$ & $\begin{array}{c}1.501 \\
\pm 0.02^{\mathrm{a}}\end{array}$ & $\begin{array}{c}1.498 \\
\pm 0.02^{\mathrm{a}}\end{array}$ & $\begin{array}{c}1.511^{\mathrm{a}} \\
\pm 0.02^{\mathrm{a}}\end{array}$ & $\begin{array}{c}1.433 \\
\pm 0.02^{\mathrm{ab}}\end{array}$ & $\begin{array}{c}1.514 \\
\pm 0.03^{\mathrm{a}}\end{array}$ \\
\hline Diabetic & $\begin{array}{c}1.491 \\
\pm 0.03^{\mathrm{a}}\end{array}$ & $\begin{array}{c}1.368 \\
\pm 0.03^{\mathrm{b}-\mathrm{d}}\end{array}$ & $\begin{array}{c}1.311 \\
\pm 0.02^{\mathrm{cd}}\end{array}$ & $\begin{array}{c}1.296 \\
\pm 0.02^{\mathrm{cd}}\end{array}$ & $\begin{array}{c}1.293 \\
\pm 0.00^{\mathrm{d}}\end{array}$ & $\begin{array}{c}1.296 \\
\pm 0.03^{\text {cd }}\end{array}$ \\
\hline \multicolumn{7}{|c|}{$\left.\mathrm{ml}^{-1}\right)$} \\
\hline Control & $\begin{array}{c}1.28 \\
\pm 0.01^{\mathrm{b}}\end{array}$ & $\begin{array}{c}1.28 \\
\pm 0.02^{\mathrm{b}}\end{array}$ & $\begin{array}{c}1.29 \\
\pm 0.01^{\mathrm{b}}\end{array}$ & $\begin{array}{c}1.27 \\
\pm 0.01^{\mathrm{b}}\end{array}$ & $\begin{array}{c}1.26 \\
\pm 0.01^{\mathrm{b}}\end{array}$ & $\begin{array}{c}1.31 \\
\pm 0.04^{\mathrm{b}}\end{array}$ \\
\hline Diabetic & $\begin{array}{c}1.30 \\
\pm 0.02^{\mathrm{b}}\end{array}$ & $\begin{array}{c}2.24 \\
\pm 0.03^{\mathrm{a}}\end{array}$ & $\begin{array}{c}2.24 \\
\pm 0.03^{\mathrm{a}}\end{array}$ & $\begin{array}{c}2.24 \\
\pm 0.02^{\mathrm{a}}\end{array}$ & $\begin{array}{c}2.24 \\
\pm 0.03^{\mathrm{a}}\end{array}$ & $\begin{array}{c}2.25 \\
\pm 0.02^{\mathrm{a}}\end{array}$ \\
\hline
\end{tabular}

- Values are expressed as mean $\pm \mathrm{SE}$

- Different letters in the columns or rows refers to a significant difference $p \leq 0.05$ - $\mathrm{n}=7$

Serum creatinine concentration exhibited a significant $(\mathrm{p} \leq 0.05)$ elevation since 24 hours after injection compared to control, the value observed at 48 hours was significantly higher than that of 24 hours. The peak significant $(\mathrm{p} \leq 0.05)$ level of creatinine illustrated at 72 hours, 7 and 15 days (Table 7). Blood urea nitrogen BUN exhibited a significant elevation relative to the control at 48 and 72 hours whereas the level of BUN obtained in the $7^{\text {th }}$ and $15^{\text {th }}$ days was increased to be more significant $(\mathrm{p} \leq 0.05)$ than the values of both 48 and 72 hours (Table 7$)$. 
Table 7: Influence of alloxan- induced diabetes mellitus on some kidney function tests in donkeys.

\begin{tabular}{|c|c|c|c|c|c|c|}
\hline \multicolumn{7}{|c|}{ Creatinine (mg.100 $\mathrm{ml}^{-1}$ ) } \\
\hline Time & Zero & 24 hours & 48 hours & 72 hours & 7 days & 15 days \\
\hline Control & $\begin{array}{c}0.91 \\
\pm 0.00^{\mathrm{d}}\end{array}$ & $\begin{array}{c}0.91 \\
\pm 0.00^{\mathrm{d}}\end{array}$ & $\begin{array}{c}0.90 \\
\pm 0.02^{\mathrm{d}}\end{array}$ & $\begin{array}{r}0.92 \\
\pm 0.01 \mathrm{~d}\end{array}$ & $\begin{array}{r}0.91 \\
\pm 0.01^{\mathrm{d}}\end{array}$ & $\begin{array}{c}0.90 \\
\pm 0.00^{\mathrm{d}}\end{array}$ \\
\hline Diabetic & $\begin{array}{c}0.93 \\
\pm 0.01^{\mathrm{cd}}\end{array}$ & $\begin{array}{c}1.0 \\
\pm 0.02^{\mathrm{c}}\end{array}$ & $\begin{array}{c}1.22 \\
\pm 0.03^{\mathrm{b}}\end{array}$ & $\begin{array}{c}1.47 \\
\pm 0.04^{\text {a }}\end{array}$ & $\begin{array}{c}1.54 \\
\pm 0.04^{\mathrm{a}}\end{array}$ & $\begin{array}{c}1.55 \\
\pm 0.04^{\mathrm{a}}\end{array}$ \\
\hline \multicolumn{7}{|c|}{ BUN (mg.100 ml-1) } \\
\hline Control & $\begin{array}{l}12.66 \\
\pm 0.21^{\mathrm{c}}\end{array}$ & $\begin{array}{c}12.50 \\
\pm 0.22^{\mathrm{c}}\end{array}$ & $\begin{array}{r}12.50 \\
\pm 0.22^{c}\end{array}$ & $\begin{array}{c}11.83 \\
\pm 0.30^{\mathrm{c}}\end{array}$ & $\begin{array}{c}12.16 \\
\pm 0.30^{\mathrm{c}}\end{array}$ & $\begin{array}{c}11.83 \\
\pm 0.30^{\mathrm{c}}\end{array}$ \\
\hline Diabetic & $\begin{array}{l}11.66 \\
\pm 0.42^{c}\end{array}$ & $\begin{array}{c}12.83 \\
\pm 0.54^{\mathrm{c}}\end{array}$ & $\begin{array}{c}17.33 \\
\pm 0.33^{\mathrm{b}}\end{array}$ & $\begin{array}{c}17.31 \\
\pm .033^{\mathrm{b}}\end{array}$ & $\begin{array}{r}19.83 \\
\pm 1.04^{\mathrm{a}}\end{array}$ & $\begin{array}{c}19.83 \\
\pm 0.47^{\mathrm{a}}\end{array}$ \\
\hline
\end{tabular}

- Values are expressed as mean $\pm \mathrm{SE}$

- Different letters in the columns or rows refers to a significant difference $\mathrm{p} \leq 0.05$

- $\mathrm{n}=7$

As considered with serum glutathione (GSH) concentration, there was a sharp decrease just at the end of the experiment $\left(15^{\text {th }}\right.$ day $)$ as presented in Table (8) which is significantly $(p \leq 0.05)$ less than the values of both baseline and counterpart value of control group $(\mathrm{p} \leq 0.05)$. Serum malondialdehyde (MDA) elevated $(\mathrm{p} \leq 0.05)$ at 48 and 72 hours compared with both control and zero hour, MDA values of both $7^{\text {th }}$ and $15^{\text {th }}$ days were greater $(\mathrm{p} \leq 0.05)$ than both there counterparts of control on one hand or 48 and 72 hours of diabetic group on the other hand (Table 8). 
Table 8: Influence of alloxan- induced diabetes mellitus on the serum indices of oxidative stress in donkeys.

\begin{tabular}{|c|c|c|c|c|c|c|}
\hline \multicolumn{7}{|c|}{$\mathrm{GSH}\left(\mu \mathrm{mol} . \mathrm{L}^{-1}\right)$} \\
\hline $\begin{array}{l}\text { Time } \\
\text { Groups }\end{array}$ & Zero & 24 hours & 48 hours & 72 hours & 7 days & 15 days \\
\hline Control & $\begin{array}{c}2.05 \\
\pm 0.11^{\mathrm{a}}\end{array}$ & $\begin{array}{c}2.06 \\
\pm 0.11^{\text {a }}\end{array}$ & $\begin{array}{c}2.08 \\
\pm 0.09^{\mathrm{a}}\end{array}$ & $\begin{array}{c}2.06 \\
\pm 0.07^{\text {a }}\end{array}$ & $\begin{array}{r}2.06 \\
\pm 0.11^{\mathrm{a}}\end{array}$ & $\begin{array}{c}2.15 \\
\pm 0.10^{\text {a }}\end{array}$ \\
\hline Diabetic & $\begin{array}{c}2.09 \\
\pm 0.09^{\text {a }}\end{array}$ & $\begin{array}{c}2.06 \\
\pm 0.10^{\text {a }}\end{array}$ & $\begin{array}{r}2.06 \\
\pm 0.10^{\mathrm{a}}\end{array}$ & $\begin{array}{r}2.07 \\
\pm 0.09^{\text {a }}\end{array}$ & $\begin{array}{r}2.06 \\
\pm 0.17^{\text {a }}\end{array}$ & $\begin{array}{c}1.49 \\
\pm 0.16^{\mathrm{b}}\end{array}$ \\
\hline \multicolumn{7}{|c|}{$\operatorname{MDA}\left(\mu \mathrm{mol} . \mathrm{L}^{-1}\right)$} \\
\hline Control & $\begin{array}{r}0.58 \\
\pm 0.02^{c}\end{array}$ & $\begin{array}{r}0.53 \\
\pm 0.02^{c}\end{array}$ & $\begin{array}{c}0.53 \\
\pm 0.02^{c}\end{array}$ & $\begin{array}{c}0.54 \\
\pm 0.00^{c}\end{array}$ & $\begin{array}{c}0.54 \\
\pm 0.02^{\mathrm{c}}\end{array}$ & $\begin{array}{c}0.53 \\
\pm 0.02^{\mathrm{c}}\end{array}$ \\
\hline Diabetic & $\begin{array}{c}0.60 \\
\pm 0.04^{\mathrm{c}}\end{array}$ & $\begin{array}{r}0.56 \\
\pm 0.04^{\mathrm{c}}\end{array}$ & $\begin{array}{c}0.74 \\
\pm 0.03^{\mathrm{b}}\end{array}$ & $\begin{array}{c}0.83 \\
\pm 0.04^{\mathrm{b}}\end{array}$ & $\begin{array}{c}0.94 \\
\pm 0.02^{\text {a }}\end{array}$ & $\begin{array}{c}0.98 \\
\pm 0.02^{\text {a }}\end{array}$ \\
\hline
\end{tabular}

- Values are expressed as mean $\pm \mathrm{SE}$

- Different letters in the columns or rows refers to a significant difference $p \leq 0.05$

- $\mathrm{n}=7$

\section{DISCUSSION}

Hyperglycemia is the earliest logical result of alloxan injection in most species however human considered resistant to this effect, our present results are an assertion of many previous outcomes like Sikarwar and Patil (2010); Geetha et al. (2011); Rotimi et al. (2011) who reported that hyperglycemia is a common effect of insulin dependent diabetes mellitus IDDM. Hyperglycemia is the sequel of lack of circulating insulin so hepatic release of glucose is uninhibited (YkiJarvinen et al., 1984). The action of alloxan in the pancrease is preceded by it's rapid uptake by $\beta$ - cells (Boquist et al., 1983) and liver (Tiedge et al., 1997). This action has been implicated in the alloxan diabetogenicity as well as the hypothesis of the role of reactive oxygen species (ROS) formation (Heikkila et al., 1976) as Udayakumar et al. (2009) presented that one of the diabetes manifestations is the enhancement of liver enzyme, glucose 6- phosphatase activity, the key enzyme for the process of gluconeogenesis. Lenzen et al. (1992) proposed an additional mechanism for alloxan- induced hyperglycemia which suggests that alloxan reacts with two sulfhydryl groups $\mathrm{SH}$ at the 
sugar binding side of glucokinase which is essential for glycolysis and proper insulin secretion leading to the creation of disulfide bonds and inhibition of enzyme.

DNA of $\beta$ - cells is well established as a target of the rising ROS so fragmentations will take place in $\beta$ - cells exposure to alloxan (Sakurai and Ogiso, 1995). The damaged DNA stimulates poly ADP ribosylation which can partially regulates DNA reformation (LeDoux et al., 1988). Enzymatic and non enzymatic antioxidants also participate to some extent in the process of cell protection against alloxan- induced damage (Jớrns et al., 1999), which may delay the sharp hyperglycemia. This hypothesis explains why did glucose elevation in this study did not detected until 24 hours of alloxan injection.

Means of glucose presented in figure 2 demonstrates that the onset of hyperglycemia commenced since 24 hours of alloxan injection however no detection of the early stage of hypoglycemia which must follow alloxan injection, this suggests that this stage might be detected in the donkeys between the $2^{\text {nd }}$ and $6^{\text {th }}$ hours after injection.

Hypercholesterolemia and hypertriglyceridemia is often arise from the state of diabetic hyperglycemia. This is similar to data of both Kheder, (2007); Geetha et al. (2011). The effect produced by insulin deficiency and it's most prominent feature, hypercholesterolemia attributed to the mobilization of fats from peripheral adipose tissues due to underutilization of glucose (Nimenibo-Uadia, 2003). The lack of insulin inhibitory action of lipase and related elevation of counter regulatory hormones lead to activation of lypolytic enzymes in adipose tissues, acyl Co-A: Cholesterol acyl transferase, the enzyme engaging a role in the intestinal absorption of cholesterol which is up regulated during insulin deficiency which can be elucidates another aspect of the hypercholesterolemia (Hori et al., 2004). Furthermore, lipoprotein lipase may be inhibited as a consequence of insulin deficiency and hypertriglyceridemia will be common resulted from diminished rate of triglycerides mobilization into glycerol and free fatty acids (Nelson and Cox, 2005).

Regarding serum proteins concentration, present study demonstrated a condition of hyperproteinemia and hyperalbuminemia resulted from experimental diabetes in the donkeys counterwise to the most studies Udayakumar et al. (2009); Mansour et al. (2002) who subjected lab. animals to alloxan. These studies interpreted diabetic 
hypoproteinemia as a result of negative nitrogen balance, enhanced proteolysis and lowered protein synthesis in the case of lack of insulin (Pathak and Dhawan, 1998). The reports of Peavy et al. (1978) described the metabolic effect of hypoproteinemia and the sequence hypoalbuminemia as an outcome of decreased level of albumin mRNA in the liver of diabetic animals while Pushkina et al. (1987) reported that there is no alteration in serum proteins during experimental diabetes. However the observations of present study resembled that of Kheder, (2007) who detected a significant $(p \leq 0.05)$ hyperproteinemia following the induction of diabetes. The findings might be explained as a result of diabetic polyurea and consequence dehydration and hemococentration (Khan and Hershey 2001).

Liver enzymes including alanine aminotransferase (ALT) and aspartate aminotransferase (AST) are elevated as a result of alloxaninduced diabetes mellitus which agree with Udayakumar et al. (2009); Hamden et al. (2009a). Transaminases are directly related to changes in the metabolic activities in which the enzymes are involved. Both ALT and AST activities might increased during insulin deficiency because of the availability of amino acids in blood as well as the implication of increased gluconeogenesis and ketogenesis (Gokce and Haznedaroglu, 2008), also alloxan- induced liver damage might be partially responsible for elevated transaminases activity, the findings based on decreased activity of both ALT and AST in the liver of diabetic rats in contrast elevation in plasma (Mansour et al., 2002).

Gamma glutamyl transferase GGT and alkaline phosphatase ALP activities are also elevated in the present study likewise Udayakumar et al. (2009); Hamden et al. (2009b). Both GGT and ALP acts as indicators of liver function hence the disturbance of their plasma activity indicates abnormal liver function which attributes to alloxan- induced lipid peroxides (LPO) mediated tissue damage in pancrease, liver, kidney and heart (Prince et al., 1997). So increased activity of these two enzymes in this trail may be a result of leaking out from tissues into the circulation through alteration membrane's architecture. The event enhances liver enzymes activity in plasma (Prince and Menon, 2000).

An elevated creatine phosphokinase CPK activity in the present study is in agreement with the findings of Kain et al. (2010) and it can be elucidated as a score of cardiac complications and damage represented as heart infarction (Howard-Alpe et al., 2006). Amylase activity did not reflect a clear cut significant values however previous 
studies demonstrates a decline in amylase activity as a result of diabetes in lab. animals (Otsuki and Williams, 1982; Pierzynowski and Barej, 1984) which may reflect a species variations in donkeys compared to others.

The level of total bilirubin insignificantly decreased. This observations did not harmonized with both Hamden et al., (2009a); Mansour et al. (2002) and who reported a condition of hyperbilirubinemia in alloxan- induced diabetic rats. On the other hand, Takayanagi et al. (2011) demonstrated that diabetes might induce hypobilirubinemia as an of inverse correlation between diabetic hyperglycemia and level of plasma bilirubin a fact of equine feature in bilirubin excretion. Hemoglobin $(\mathrm{Hb})$ concentration in the present study also kept on the same basal level with no diabetic- induced alteration in the blood of treated donkeys.

Insignificant changes in serum sodium $\left(\mathrm{Na}^{+}\right)$concentration observed from alloxan- injected donkeys was evident whereas a few previous studies differed about this aspect when Ikpi et al. (2009) referred to a status of decreased plasma concentration of sodium as a result of alloxan- induced diabetes in rats. However our present observations stayed in agreement with Soto et al. (2001). Potassium $\left(\mathrm{K}^{+}\right)$ also considered insignificant changed similarly in diabetic donkeys when compared with baseline value although a significant hypokalemia observed in both 48 hours and 7 days after alloxan injection in respect to control only. A fact which was partially agreed with Dhawan et al. (1999) in diabetic rats. On the contrary, Kpi et al. (2009) who did not report any alteration in potassium level.

The reduced serum calcium $\left(\mathrm{Ca}^{+2}\right)$ confirms the findings of Duarte et al. (2005), a result which can be explicated as a result of diabetic lipidemia and it's significant impact to impair $\mathrm{Ca}^{+2}$ efflux from the cell (Witczak and Sturek, 2004). Elevated extracellular glucose concentration triggers the opening of $\mathrm{Ca}^{+2}$ channels and consequence influx of $\mathrm{Ca}^{+2}$ into the cells which serves as critical trigger for insulin exocytosis process (Laughlin et al., 1989). The disturbances in the intracellular $\mathrm{Ca}^{+2}$ homeostasis considered an important step in the diabetogenic effect of alloxan which demonstrated as alloxan- induced elevation in cytosolic free $\mathrm{Ca}^{+2}$ in $\beta$ - cells (Park et al., 1995). The change may also arises from exaggerated mobilization from intracellular medium and it's limited elimination from the cytoplasm. $\mathrm{Ca}^{+2}$ influx may result from alloxan ability to depolarize $\beta$ - cells (Dean and Matthews, 
1972). Depolarization of cell membrane enhances the opening of voltage- dpendent $\mathrm{Ca}^{+2}$ channels and increases $\mathrm{Ca}^{+2}$ entry into the cells (Lenzen et al., 1992).

Alloxan- induced restriction of $\mathrm{Ca}^{+2}$ removal from the cells due to alloxan- induced inhibition of liver plasma membrane $\mathrm{Ca}^{+2}-$ ATPase was reported (Seckin et al., 1993). So the result of these events is hypocalcemia which confirms our data. Park et al., (1995) interpreted the effect of alloxan on cell $\mathrm{Ca}^{+2}$ as a consequence of elevated hydrogen peroxide $\mathrm{H}_{2} \mathrm{O} 2$ accompany alloxan administration.

Hyperphosphatemia affirms the observations of Mahmud et al. (2011) versus to Bicer et al. (2011) who recorded the reverse result in diabetic rats. Also Duarte et al. (2005) did not recorded a significant alteration in the serum inorganic phosphate resulted from alloxan treatment. In vitro, cell incubation with alloxan yields an activation of ALP activity in rat kidney and small intestine (Parsadanian et al., 1989) Also alloxan- induced hyperphosphatemia suggests that diabetic status and resulted ketoacidosis prohibits the uptake of glucose and inorganic phosphate by the insulin- sensitive cells (Ditzel and Lervang, 2010).

It has been well established that the elevation of both creatinine and blood urea nitrogen BUN is a common result of diabetes mellitus which is in agreement with Hamden et al. (2009b); Tavafi et al. (2011). Early stages of diabetic nephropathy characterized by glomerular hyperfiltration which increases glomerular filtration rate (GFR) and it is contributes to the progression of nephropathy (Sochett et al., 2006). Also there was a down- regulation of nitric oxide synthase binding sites in addition to a reduction in NADPH- diaphorase activity in the diabetic renal cortex, medulla and glomeruli (Mumtaz et al., 2004). Winiarska et al. (2011) documented that diabetes- induced elevated NADPH oxidase activity catalyses superoxide radical formation which implicated to be the source of ROS in kidney. Thus the development of diabetic nephropathy is prevailing. Evan et al. (1984) proved the prejudicial role of alloxan on kidney of lab animals through a histopathological study which revealed a focal glomerular basement membrane thickening as well as glomerular capillary endothelial abnormalities and visceral foot process fusion and reduction in the size of endothelial fenestae. Furthermore, alloxan- induced activation in sphingosine kinasesphingosine 1- phosphate signaling pathway might be involved in the pathogenesis of diabetic nephropathy and renal injury (Lan et al., 2010). 
The state of hyperglycemia discussed above beside to the increased ROS production resulted from alloxan injection are implicated in motivating the formation of ROS creating an oxidative atmosphere in the cells through impairment the endogenous antioxidant system (West, 2000). Reduced glutathione GSH protects the cellular system against the detrimental effect of LPO (Nicotera and Orrenius, 1986) and also serves as a free radical scavenger, co- substrate for glutathione peroxidase GSHpx as well as GSH forms conjugates in xenobiotic reactions (Gregus et al., 1996). So the elevated serum GSH observed in this study might be explored as a result of alloxan and it's reduced product dialuric acid when they reacts with oxygen yields superoxide radical $\mathrm{O}_{2}^{-2}$ and hydrogen peroxide $\mathrm{H}_{2} \mathrm{O}_{2}$ and in the presence of $\mathrm{O}^{-} 2$. The formation of hydroxyl radical $\mathrm{OH}^{-}$is predicted leading to peroxidation of numerous biomolecules including proteins (Halliwell and Gutteridge, 1985). Damaged protein is a common reason for the decreased activity of GSH$\mathrm{S}$ transferase, GSH reductase and glucose 6- phosphate dehydrogenase (Letelier et al., 2005), the enzymes responsible for GSH biosynthesis and reactivation.

Kochar and Umathe, (2009) recorded a decrease in GSH beside increase in malondialdehyde MDA as well as a decrease in the activity of antioxidant enzymes including superoxide dismutase SOD and catalase CAT. These findings confirms the observations of Fisher and Humburger, (1980) in pancreatic islets, erythrocytes (Yadav et al., 1996), kidney (Kêdziora-Kornatowska et al., 2002), liver and testis (El-Missiry and El Gindy, 2000) which attributed to inactivation of mitochondrial and cytosolic antioxidant enzymes due to decreased their protein expression levels in the diabetic conditions (Sindhu et al., 2004).

Thiobarbituric acid reacting substance (MDA) which represents one of the lipid peroxidation products was elevated as a result of alloxan injection, a result can be explained on the base of previous in vitro study observed that occurrence of glucose enolization results in reduction of molecular oxygen and production of oxygen free radicals and $\alpha$ ketoaldehydes which ultimately cause peroxidative breakdown of phospholipids and accumulation of MDA (Kochar and Umathe, 2009).

\section{ACKNOWLEDGMENT}

The study supported by College of Veterinary Medicine, University of Mosul. Author acknowledge Dr. Nabeel A. J. Al- Hussary For chemicals supply. 


\section{REFERENCES}

Alkharfy, K.M. (2009): Influence of overt diabetes mellitus on cyclosporine pharmacokinetics in a canine model. Exp. Diabetes Res. 363787.

Beuge, J.A. and Aust, S.D. (1978): Estimation of serum malondialdehyde level. London: Academic Press.

Bicer, M.; Akil, M.; Sivrikaya, A.; Kara, E.; Baltaci, A.K. and Mogulkoc, $R$. (2011): Effect of zinc supplementation on the distribution of various elements in the serum of diabetic rats subjected to an acute swimming exercise. J. Physiol. Biochem. (under press).

Boquist, L.; Nelson, L. and Lorentzon, R. (1983): Uptake of labelled alloxan in mouse organs and mitochondria in vivo and in vitro. Endocrinology. 113: 943-948.

Burtis, C.A. and Ashwood, E.R. (1999): Tietz textbook of clinical chemistry. $3^{\text {rd }}$ ed. New York: W.B. Saunders.

Carver, T.D.; Anderson, S.M.; Aldoretta, P.A.; Esler, A.L. and Hay, $W . W . J r$. (1995): Glucose suppression of insulin secretion in chronically hyperglycemic fetal sheep. Pediatr. Res. 38(5): 754-762.

Dean, P.M. and Matthews, E.K. (1972): The bioelectrical properties of pancreatic islet cells: effect of diabetogenic agents. Diabetologia. 8: 173-178.

Dhawan, D.; Singh, A.; Singh, B.; Bandhu, H.K.; Chand, B. and Singh, $N$. (1999): Effect of lithium augmentation on the trace elemental profile in diabetic rats. Biometals. 12(4):375-381.

Ditzel, J. and Lervang, H-H. (2010): Disturbance of inorganic phosphate metabolism in diabetes mellitus: clinical manifestations of phosphorus-depletion syndrome during recovery from diabetic ketoacidosis. Diabetes Metab. Syndr. Obes. 3: 319-324.

Duarte, V.M.; Ramos, A.M.; Rezende, L.A.; Macedo, U.B.; BrandlfoNeto, J.; Almeida, M.G. and Rezende, A.A. (2005): Osteopenia: a bone disorder associated with diabetes mellitus. J. Bone. Miner. Metab. 23(1): 58-68.

Duncan, D.B. (1955): Multiple range and multiple "F" test. Biometric. 11: 1-42.

Durham, A.E.; Hughes, K.J.; Cottle, H.J.; Rendle, D.I. and Boston, R.C. (2009): Type 2 diabetes mellitus with pancreatic beta cell dysfunction in 3 horses confirmed with minimal model analysis. Equine Vet. J. 41(9): 924-929. 
El-Missiry, M.A. and El Gindy, A.M. (2000): Amelioration of alloxan induced diabetes mellitus and oxidative stress in rats by oil of Eruca sativa seeds. Ann. Nutr. Metab. 44: 97-100.

Evan, A.P.; Mong, S.A.; Connors, B.A.; Aronoff, G.R. and Luft, F.C. (1984): The effect of alloxan, and alloxan-induced diabetes on the kidney. Anat. Rec. 208(1): 33-47.

Fisher, J. and Humburger, S.A. (1980): Inhibition of alloxan action in isolated pancreatic islets by superoxide dismutase, catalase, and metal chelator. Diabetes. 29: 213-216.

Fox, J.G.; Cohen, B.J. and Loew, F.M. (1997): Laboratory animal medicine. London: Academic Press, pp: 119-120.

Geetha, G.; Kalavalarasariel Gopinathapillai, P. and Sankar, V. (2011): Anti diabetic effect of Achyranthes rubrofusca leaf extracts on alloxan induced diabetic rats. Pak. J. Pharm. Sci. 24(2): 193-199.

Ghosh, T.; Maity, T.K. and Singh, J. (2010): Antihyperglycemic activity of bacosine, a triterpene from bacopa monnieri, in alloxanInduced diabetic rats. Planta. Med. (under press).

Gokce, G. and Haznedaroglu, M.Z. (2008): Evaluation of antidiabetic, antioxidant and vasoprotective effects of Posidonia oceanica extract. J. Ethnopharmacol. 115: 122-130.

Gregus, Z.; Fekete, T.; Halászi, E. and Klaassen, C.D. (1996): Lipoic acid impairs glycine conjugation of benzoic acid and renal excretion of benzoylglycine. Drug. Metab. Dispos. 24: 682-688.

Gupta, S.; Chattopadhyay, T.; Pal Singh, M. and Surolia, A. (2010): Supramolecular insulin assembly II for a sustained treatment of type 1 diabetes mellitus. Proc. Natl. Acad. Sci. 107(30): 13246-13251.

Halliwell, B. and Gutteridge, J.M.C. (1985): Free Radicals in Biology and Medicine. Oxford: Calderon Press.pp. 62-69.

Hamden, K.; Boujbiha, M.A.; Masmoudi, H.; Ayadi, F.M.; Jamoussi, K. and Elfeki, A. (2009a): Combined vitamins (C and E) and insulin improve oxidative stress and pancreatic and hepatic injury in alloxan diabetic rats. Biomed. Pharmacother. 63(2): 95-99.

Hamden, K.; Carreau, S.; Jamoussi, K.; Miladi, S.; Lajmi, S.; Aloulou,

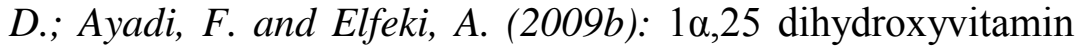
D3: Therapeutic preventive effects against oxidative stress, 
hepatic, pancreatic and renal injury in alloxan-induced diabetes in rats. Nutr. Sci. Vitaminol. 55: 215-222.

Heikkila, R.E.; Winston, B.; Cohen, G. and Barden, H. (1976): Alloxan induced diabetes, evidence for hydroxyl radicals as a cytotoxic intermediate. Biochem. Pharmacol. 25: 1085-1092.

Hori, M.; Satoh, M.; Furukawa, K.; Sakamoto, Y.; Hakamata, H. and Komahara, Y. (2004): Acyl- Co A: cholesterol acyl transferase2 (ACAT-2) is responsible for elevated intestinal ACAT activity in diabetic rats. Arterioscler. Thromb. Vasc. Biol. 24: 1689-1695.

Howard-Alpe, G.M.; Sear, J.W. and Foex, P. (2006): Methods of detecting atherosclerosis in non-cardiac surgical patients; the role of biochemical markers. Br. J. Anaesth. 97(6): 758-769.

Ikpi, D.E.; Obembe, A.O. and Nku, C.O. (2009): Aqueous leaf extract of Rothmannia longiflora improves basal metabolic rate and electrolyte parameters in alloxan-induced diabetic rats. Niger. J. Physiol. Sci. 24(1): 67-71.

Jelodar, G.; Razmi, N. and Gholampour, V. (2007): Arginase alteration in the reproductive system of alloxan-diabetic dogs. J. Reprod. Dev. 53(2): 317-321.

Jórns, A.; Tiedge, M.; Lenzen, S. and Muday, R. (1999): Effect of superoxide dismutase, catalase, chelating agents and free radical scavengers on the toxicity of alloxan to isolated pancreatic islets in vitro. Free Radic. Biol. Med. 26: 1300-1304.

Kain, V.; Kumar, S.; Puranik, A.S. and Sitasawad, S.L. (2010): Azelnidipine protects myocardium in hyperglycemia-induced cardiac damage. Cardiovasc. Diabetol. 9: 82-86.

Kaneko, J.J.; Harvey, J.W. and Bruss, M.L. (1997): Clinical biochemistry of domestic animals, $5^{\text {th }}$ ed., Academic Press. pp: 68-74.

Kêdziora-Kornatowska, K.; Szram, S.; Kornatowski, T.; SzadujkisSzadurski, L.; Kêdziora, J. and Bartosz, G. (2002): The effect of verapamil on the antioxidant defence system in diabetic kidney. Clin. Chim. Acta. 322: 105-112.

Khan, N.M. and Hershey, O. (2001): Update on screening for type 2 diabetes they, why, who, how and what of testing and diagnosing. Postgraduate Medicine. 109(2): 111-119.

Kheder, A.E. (2007): The effect of dexamethasone on some biochemical parameters of normal and alloxan- induced diabetic rats. 
Master thesis. College of Veterinary Medicine. University of Mosul.

Kochar, N.I. and Umathe, S.N. (2009): Beneficial effects of L-arginine against diabetes-induced oxidative stress in gastrointestinal tissues in rats. Pharmacological reports. 61: 672-685.

Ladosky, E.M. and Fonteles, M.C. (1988): Presynaptic changes promoted by alloxan diabetes in the cat isolated heart. J. Pharm. Pharmacol. 40(5): 362-364.

Lan, T.; Shen, X.; Liu, P.; Liu, W.; Xu, S.; Xie, X.; Jiang, Q.; Li, W. and Huang, H. (2010): Berberine ameliorates renal injury in diabetic C57BL/6 mice: Involvement of suppression of SphKS1P signaling pathway. Arch. Biochem. Biophys. 502(2): 112-120.

Laughlin, M.H.; Overholser, K.A. and Bhatte, M.J. (1989): Exercise training increases coronary transport reserve in miniature swine. J. Appl. Physiol. 67: 1140-1149.

LeDoux, S.P.; Hall, C.R.; Forbes, P.M.; Patton, N.J. and Wilson, G.L. 1988): Mechanisms of nicotinamide and thymidine protection from alloxan and streptozotocin toxicity. Diabetes. 37: 1015-1019.

Lenzen, S.; Brǘnig, H. and Mǘnster, W. (1992): Effects of alloxan and ninhydrin on mitochondrial $\mathrm{Ca}^{2+}$ transport. Mol. Cell. Biochem. 118: 141-151.

Letelier, M.E.; Lepe, A.M.; Faundez, M.; Salazar, J.; Marin, R.; Aracena, P. and Speiski, H. (2005): Possible mechanisms underlying copper-induced damage in biological membranes leading to cellular toxicity. Chem. Biol. Interact. 151:71-82.

Mahmud, I.; Rahman, Z.; Keka, S.I.; Devnath, S.; Masum, N. and Hossian, S. (2011): Hyperphosphataemia is associated with the diabetes-related cardiovascular risk factors. Journal of Oleo Science. 60(2):79-85.

Mansour, H.A.; Newairy, A.S.; Yousef, M.I. and Sheweita, S.A. (2002): Biochemical study on the effects of some Egyptian herbs in alloxan-induced diabetic rats. Toxicology. 170(3):221-228.

McKenzie, J.; Fisher, B.M.; Jaap, A.J.; Stanely, A.; Paterson, K. and Sattar, N. (2006): Effects of HRT on liver enzyme levels in women with type 2 diabetes: a randomized placebo- controlled trial. Clin. Endocrinol. 65(1): 4-40.

Medical dictionary. http://encyclopedia2.thefreedictionary.com/alloxan. 
Mumtaz, F.H.; Dashwood, M.R.; Khan, M.A.; Thompson, C.S.; Mikhailidis, D.P. and Morgan, R.J. (2004): Down-regulation of nitric oxide synthase in the diabetic rabbit kidney: potential relevance to the early pathogenesis of diabetic nephropathy. Curr. Med. Res. Opin. 20(1): 1-6.

National Diabetes Fact Sheet. (2007): Department of Health and Human Services. Centers for Disease Control and Prevention.

http://www.cdc.gov/diabetes/pubs/pdf/ndfs_2007pdf

Nelson, D.L. and Cox, M.M. (2005): Lehninger principles of biochemistry. $4^{\text {th }}$ ed. New York: Freeman Company.

Nicotera, P. and Orrenius, S. (1986): Role of thiols in protection against biological reactive intermediates. Adv. Exp. Med. Biol. 197: 41-49.

Nimenibo-Uadia, R. (2003): Effect of aqueous extract of Canavalia ensiformis seeds on hyperlipidaemic and hyperketonaemia in alloxan-induced diabetic rats. Biokemistri. 15: 7-15.

Okamoto, T.; Oikawa, S. and Toyota, T. (1990): Absence of angiogenesis-inhibitory activity in aqueous humor of diabetic rabbits. Diabetes. 39(1): 6-12.

Otsuki, M. and Williams, J.A. (1982): Effect of diabetes mellitus on the regulation of enzyme secretion by isolated rat pancreatic acini. J. Clin. Invest. 70(1): 148-156.

Pacal, L.; Varvarovska, J.; Rusavy, Z.; Lacigova, S.; Stetina, R.; Racek, J.; Pomahacova, R.; Tanhauserova, V. and Kankova, K. (2011): Parameters of oxidative stress, DNA damage and DNA repair in type 1 and type 2 diabetes mellitus. Arch. Physiol. Biochem. [Epub a head of print].

Park, B.H.; Rho, H.W.; Park, J.W.; Cho, C.G.; Kim, J.S.; Chung, H.T. and Kim, H.R. (1995): Protective mechanism of glucose against alloxan- induced pancreatic beta-cell damage. Biochem. Biophys. Res. Commun. 210: 1-6.

Parsadanian, G.K.; Sarkisian, L.V.; Aslanian, I.G.; Adunts, G.T. and Adunts, G.G. (1989): The effect of alloxan on activity of various enzymes of phosphorus metabolism in vitro. Vopr. Med. Khim. 35(5): 23-26.

Pathak, A. and Dhawan, D. (1998): Effect of lithium on the levels of blood urea and creatinine in diabetic rats. Med. Sci. Res. 26: 855 .

Paul, S.; Bandyopadhyay, T.K. and Bhattacharyya, A. (2011): Immunomodulatory effect of leaf extract of Murraya koenigii 
in diabetic mice. Immunopharmacol. Immunotoxicol. [Epub ahead of print].

Peavy, D.E.; Taylor, J.M. and Jefferson, L.S. (1978): Correlation of albumin production rates and albumin mRNA levels in livers of normal, diabetic, and insulin-treated diabetic rats. Proc. Natl. Acad. Sci. 75(12): 5879-5883.

Pierzynowski, S. and Barej, W. (1984): The dependence of exocrine pancreatic secretion on insulin in sheep. Quarterly Journal of Experimental Physiology. 69: 35-39.

Prince, P.S.M. and Menon, V.P. (2000): Hypoglycaemic and other related actions of Tinospora cardifolia roots in alloxan induced diabetic rats. J. Ethnopharmacol. 70: 9-15.

Prince, P.S.M.; Menon, V.P. and Pari, L. (1997): Effect of Syzigium cumini extracts on hepatic hexokinase and glucose-6phosphatase in experimental diabetes. Phytother. Res. 11: 529-531.

Pushkina, N.V.; Tsybul'ski, I.E. and Lukash, A.I. (1987): Amidation of blood proteins during hyperglycemia in experimental diabetes mellitus. Vopr. Med. Khim. 33(4): 52-55.

Reiser, H.J.; Whitworth, U.G. Jr.; Hatchell, D.L.; Sutherland, F.S.; Nanda, S.; McAdoo, T. and Hardin, J.R. (1987): Experimental diabetes in cats induced by partial pancreatectomy alone or combined with local injection of alloxan. Lab. Anim. Sci. 37(4): 449-452.

Rotimi, S.O.; Omotosho, O.E. and Rotimi, O.A. (2011): Persistence of acidosis in alloxan-induced diabetic rats treated with the juice of Asystasia gangetica leaves. Pharmacogn. Mag. 7(25):25-30.

Sakurai, K. and Ogiso, T. (1995): Effect of ferritin on $\lambda$ DNA strand breaks in the reaction system of alloxan plus NADPHcytochrome P450 reductase: ferritin's role in diabetogenic action of alloxan. Biol. Pharm. Bull. 18: 262-266.

Sboui, A.; Khorchani, T.; Djegham, M.; Agrebi, A.; Elhatmi, H. and Belhadj, O. (2010): Anti-diabetic effect of camel milk in alloxan-induced diabetic dogs: a dose-response experiment. J. Anim. Physiol. Anim. Nutr. 94(4): 540-546.

Seckin, S.; Alptekin, N.; Nocak-Toker, N. and Uysal, M. (1993): Liver plasma membrane and erythrocyte $\mathrm{Ca}^{+2}$ ATPase activities in alloxan-rats. Med. Sci. Res. 21: 539-540. 
Sikarwar, M.S. and Patil M.B. (2010): Antidiabetic activity of Pongamia pinnata leaf extracts in alloxan-induced diabetic rats. Int. J. Ayurveda. Res. 1(4): 199-204.

Sindhu, R.K.; Koo, J.R.; Roberts, C.K. and Vaziri, N.D. (2004): Dysregulation of hepatic superoxide dismutase, catalase and glutathione peroxidase in diabetes response to insulin and antioxidant therapies. Clin. Exp. Hypertens. 26: 43-53.

Smith, S.B. and Prior, R.L. (1984): Metabolic responses to fasting and alloxan-induced diabetes mellitus in steers. Am. J. Vet. Res. 45(9): 1829-1834.

Sochett, E.B.; Cherney, D.Z.; Curtis, J.R.; Dekker, M.G.; Scholey, J.W. and Miller, J.A. (2006): Impact of renin angiotensin system modulation on the hyperfiltration state in type 1 diabetes. J. Am. Soc. Nephrol. 17: 1703-1709.

Soto, C.; Del Razo, L.M. and Neri, L. (2001): Alloxan decreases intracellular potassium content of the isolated frog skin epithelium. Comp. Biochem. Physiol. C. Toxicol. Pharmacol. 130(1): 19-27.

Steel, R.G.D. and Torrie, J.H. (1980): Principles and procedures of statistic. $2^{\text {nd }}$ ed., New York: Mc- Graw Hill Book Company.

Szkudelski, T. (2001): The mechanism of alloxan and streptozotocin action in B cells of the rat pancreas. Physiol. Res. 50: 536-546.

Takayanagi, R.; Inoguchi, T. and Ohnaka, K. (2011): Clinical and experimental evidence for oxidative stress as an exacerbating factor of diabetes mellitus. J. Clin. Biochem. Nutr. 48(1): 72-77.

Tavafi, M.; Ahmadvand, H.; Tamjidipoor, A.; Delfan, B. and Khalatbari, A.R. (2011): Satureja khozestanica essential oil ameliorates progression of diabetic nephropathy in uninephrectomized diabetic rats. Tissue Cell. 43(1):45-51.

Taylor, R. and Agius, L. (1988): The biochemistry of diabetes. Biochem. J. 250: 625-640.

Tiedge, M.; Lortz, S.; Drinkgern, J. and Lenzen, S. (1997): Relation between antioxidant enzyme gene expression and antioxidative defense status of insulin- producing cells. Diabetes. 46: 1733-1742.

Udayakumar, R.; Kasthurirengan, S.; Mariashibu, T.S.; Rajesh, M.; Anbazhagan, V.R.; Kim, S.C.; Ganapathi, A. and Choi, CW. (2009): Hypoglycaemic and hypolipidaemic effects of 
Withania somnifera root and leaf extracts on alloxan-induced diabetic rats. Int. J. Mol. Sci. 10(5): 2367-2382.

Wang, Z.; Li, L.; Zheng, F.; Jia, C.; Ruan, Y. and Li, H. (2011): Correlation between the amplitude of glucose excursion and the oxidative/antioxidative system in subjects with different types of glucose regulation. Biomed. Environ. Sci. 24(1):68-73.

West, I.C. (2000): Radicals and oxidative stress in diabetes. Diabetic. Med. 17: 171-180.

Winiarska, K.; Grabowski, M. and Rogacki, M.K. (2011): Inhibition of renal gluconeogenesis contributes to hypoglycaemic action of NADPH oxidase inhibitor, apocynin. Chem. Biol. Interact. 189(1-2): 119-126.

Witczak, C.A. and Sturek, M. (2004): Exercise prevents diabetes-induced impairment in superficial buffer barrier in porcine coronary smooth muscle. J. Appl. Physiol. 96: 1069-1079.

Yadav, P.; Sarkar, S.; Rathor, N.; John, S.; Kale, M. and Bhatnagar, D. (1996): Ascorbic acid counteracts the prooxidant effect of alloxan in erythrocytes in vitro. Curr. Sci. 71: 404-406.

Yki-Jarvinen, H.; DeFronzo, R.A. and Koivisto, V.A. (1984): Normalization of insulin sensitivity in type 1 diabetic subjects. Diabetes Care. 7: 520-527. 